\title{
Natural hazards in the mountainous region of Rio de Janeiro state, Brazil: rainfall erosivity as an early warning index
}

\author{
Geovane Alves ${ }^{1}$, Carlos de $\mathrm{Mello}^{1}, \mathrm{Li} \mathrm{Guo}^{2}$, and Michael Thebaldi ${ }^{1}$ \\ ${ }^{1}$ Universidade Federal de Lavras \\ ${ }^{2}$ Sichuan University
}

June 28, 2021

\begin{abstract}
Rainfall erosivity is defined as the potential of rain to cause erosion. It has great potential for application in studies related to landslides and floods, in addition to water erosion. The objectives of this study were: i) to model the Rday using a seasonal model for the Mountainous Region of the State of Rio de Janeiro (MRRJ); ii) to adjust thresholds of the Rday index based on catastrophic events which occurred in the last two decades; and iii) to map the maximum daily rainfall erosivity (Rmaxday) to assess the region's susceptibility to rainfall hazards according to the established Rday limits. The fitted Rday model presented a satisfactory result, thereby enabling its application as an estimator of the daily rainfall erosivity in MRRJ. Events that resulted in Rday > 1,500 MJ.ha-1.mm.h-1.day-1 were those with the highest number of fatalities. The spatial distribution of Rmaxday showed that the entire MRRJ has presented values that can cause major rainfall. The Rday index proved to be a promising indicator of rainfall hazards, which is more effective than those normally used that are only based on quantity (mm) and/or intensity (mm.h-1) of the rain.
\end{abstract}

\section{Hosted file}

manuscript final june 2021.docx available at https://authorea.com/users/422373/articles/ 528097-natural-hazards-in-the-mountainous-region-of-rio-de-janeiro-state-brazilrainfall-erosivity-as-an-early-warning-index 

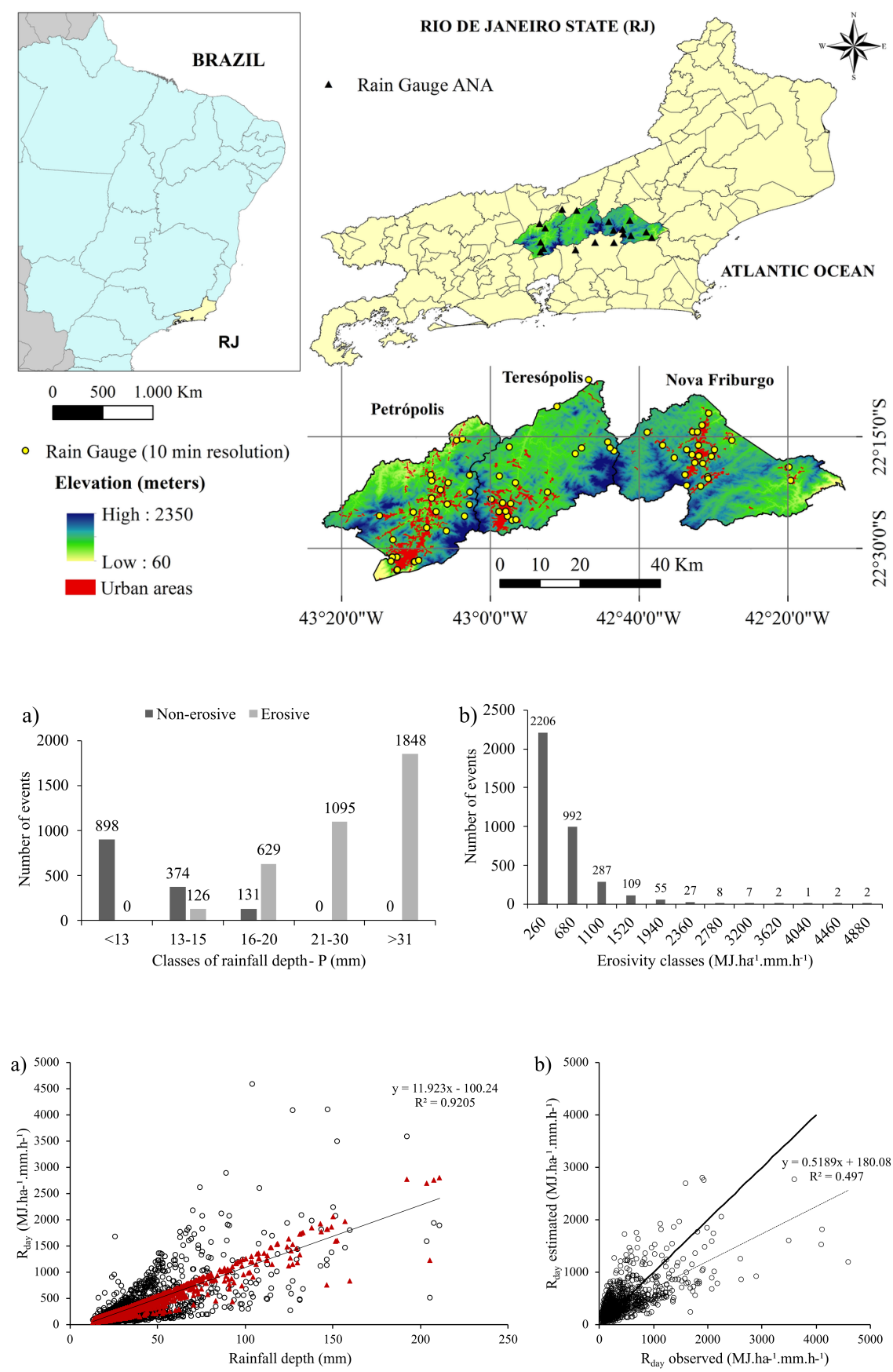

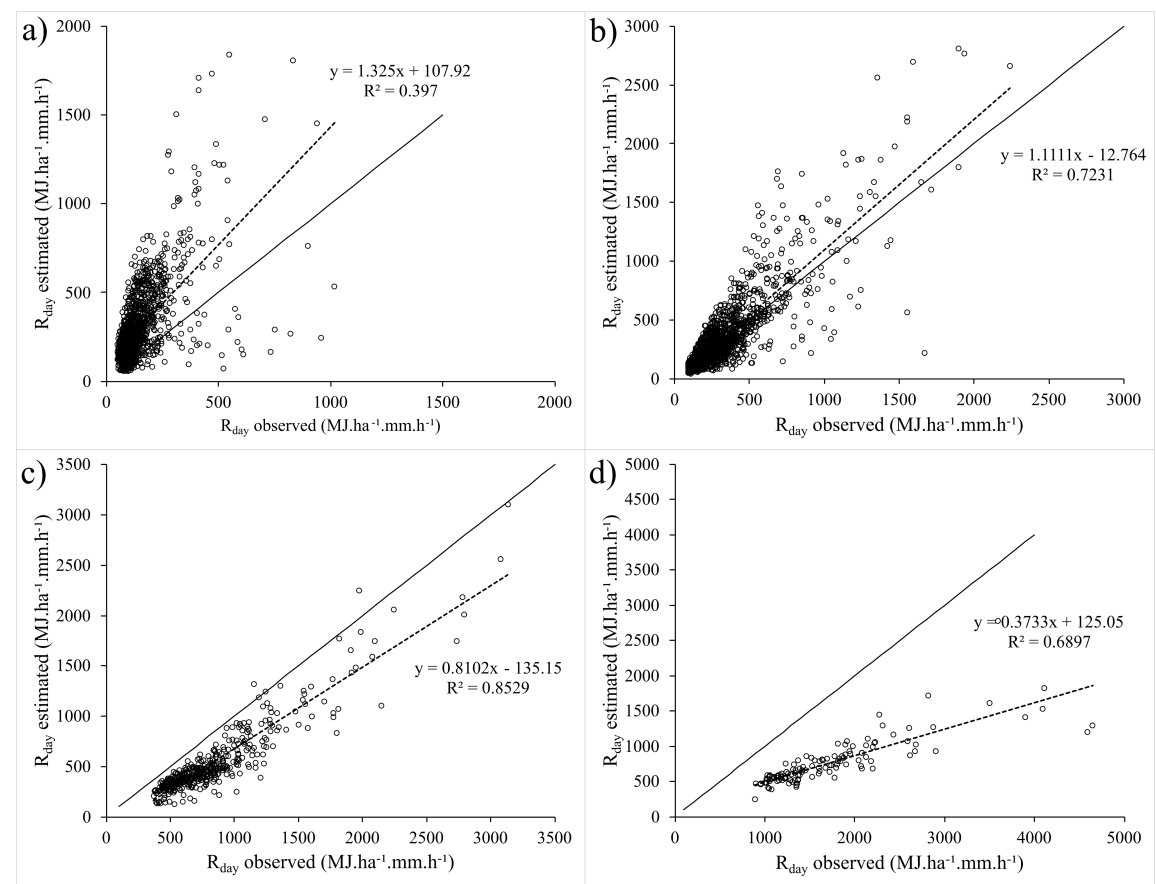


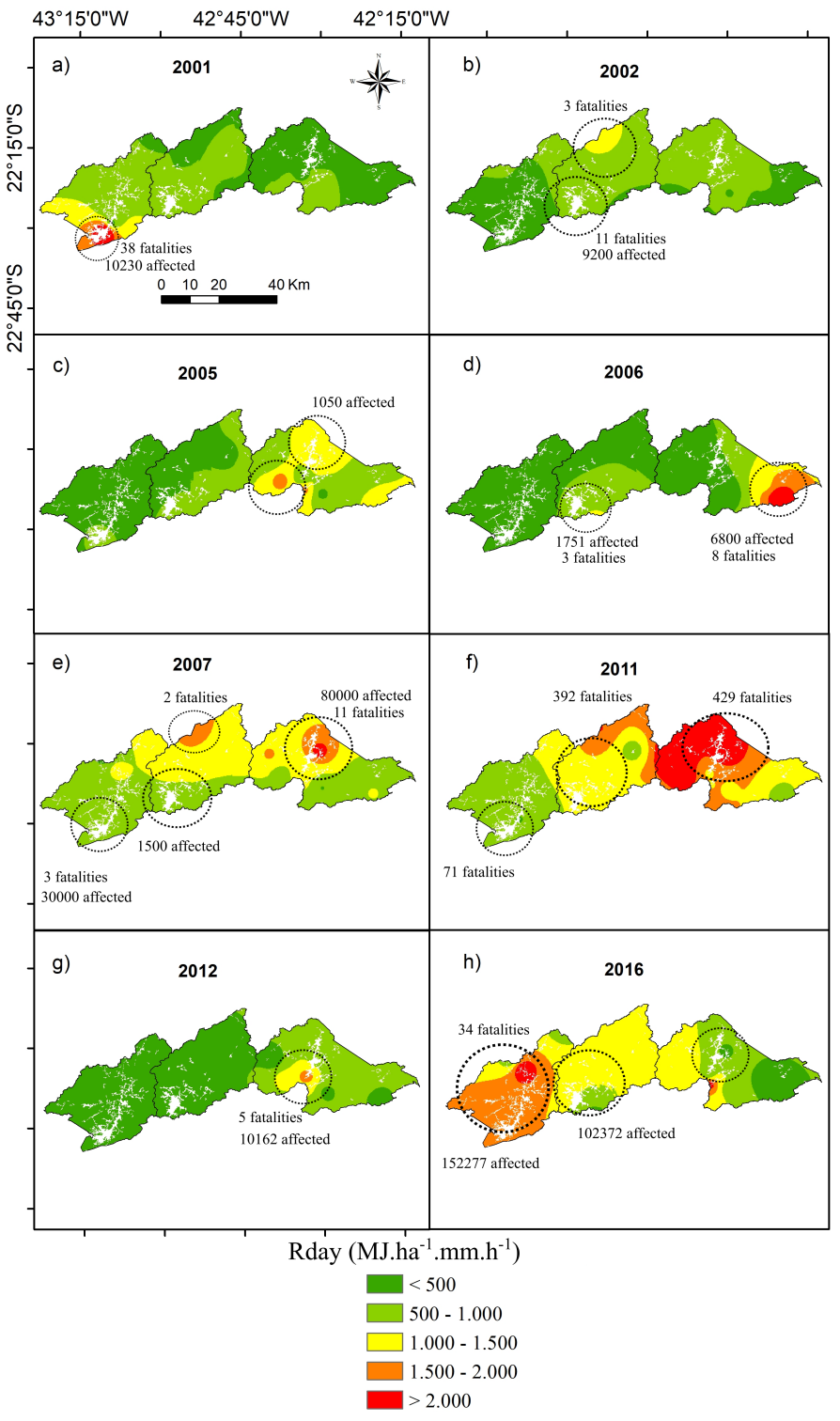




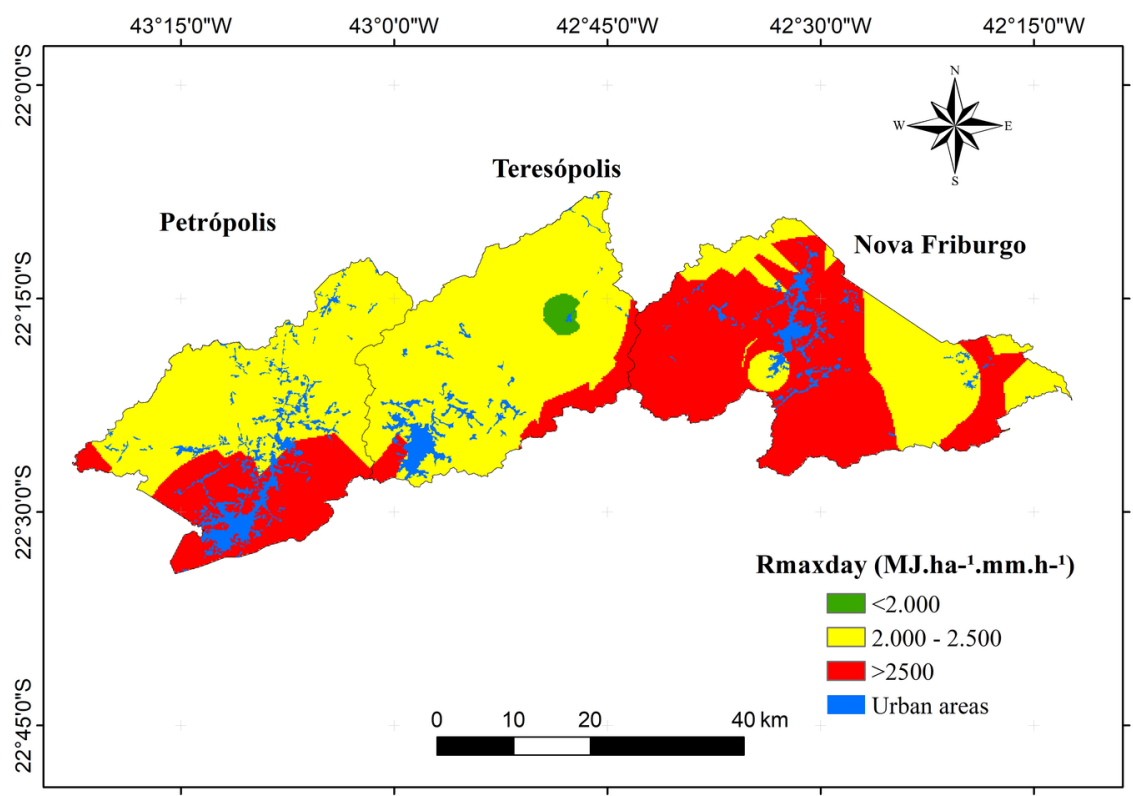

